\title{
PARTICIPATIVE DECISION-MAKING AND GAMIFICATION: THE CASE OF «CIVIC POINTS»
}

\author{
Paolo Coppola / Federico Costantini / Gabriele Franco
}

\author{
Paolo Coppola, University of Udine, Department of Mathematical, Informatics and Physical Sciences, Via delle Scienze 206, 33100 \\ Udine, IT, paolo.coppola@uniud.it \\ Federico Costantini, University of Udine, Department of Law, Via Treppo 18, 33100 Udine, IT; federico.costantini@uniud.it \\ Gabriele Franco, trainee lawyer, Lawyer's Chamber of Udine.
}

Keywords:

Gamification, Participation, E-Governance, Data Protection, GDPR, Social Credit System

Abstract: $\quad$ Although games have always been part of human history (from children's plays to gambling), only recently they have been introduced in the public sphere as a tool to stimulate aggregative social processes. However, gamification of participative decision-making, enabled by the use of ICTS and the exploitation of personal data, raises some concerns, in particular the protection of privacy and fundamental freedoms of citizens. In this contribution, after a theoretical overview, we tackle such questions, describing a participatory model which allows to minimize the risks of abuses by public authorities while maximizing the potential benefit, especially in local communities.

\section{Introduction: gamification as the new frontier in citizenship engagement}

Game is an essential component in the existence of all the most evolved animal species, both for individuals and social groups. Indeed, through playing animals transmit to their offspring several kinds of knowledge, such as survival skills, hunting techniques and herd rules. According to influential studies, we can classify different types of game - from the «paidia», namely the purely recreative and unrestrained game, to the «lu$d u s »$, which is a structured and organized competition - based on four criteria: «agōn», the competition and the quest for victory over the adversary; «alea», the presence of chance and the consequent uncertainty in the result; «mimicry», the assignment of fictional roles to the participants; «ilix», the vertigo, which entails experimenting a kind of risk and the feeling of danger. ${ }^{1}$ For humankind, in every time and civilization, the playful dimension is crucial for nurturing cognitive skills, education development and social interaction of the individual, so that it is qualified as a fundamental right ${ }^{2}$ and as a key component of natural law. ${ }^{3}$ It has to be said that not only culture and game are so intertwined that, at the end, it can be difficult to separate them, ${ }^{4}$ but also language in itself can be conceived as a sort of game in which interlocutors interact exploring the infinite possibilities of expression provided by the communication. ${ }^{5}$ Recently, thanks to the use of online platforms, videogames have involved hundreds of millions of users, becoming a thriving sector in the world economy, both in terms of profit for business companies, and for tax revenue for States. ${ }^{6}$

\footnotetext{
CAILloIs, Les jeux et les hommes. Le masque et le vertige, Gallimard, Paris, 1958.

As stated in article 31 of The United Nations Convention on the Rights of the Child of 20 November 1989.

FINNIS, Natural law and natural rights, Clarendon Press, Oxford, 1980. According to influential studies, we can classify.

Huizinga, Homo ludens. Versuch einer Bestimmung des Spielelementes der Kultur, Pantheon, Amsterdam, 1939.

Wittgenstein, Philosophical investigations, Blackwell, Oxford, 1953.

https:/en.wikipedia.org/wiki/Video_game_industry. In most cases this social phenomena has not been specifically ruled by legislators, and regulatory bodies with enormous financial power, as those built by the federations of professional sports, have been built worldwide across the last century as private institutions. In other cases, games have been forbidden - for religious or public order concerns, for example - or special regulations have been enacted, for example, establishing a system of licensing or a monopoly, as in lottery, gambling and betting.
} 
Game has recently been analysed by the effect it has on players. ${ }^{7}$ While «serious games» involve actual games not conceived for mere entertainment, "gamification» ${ }^{8}$ is aimed at exploit game-like patterns outside the context in which it normally takes place. Specifically, its purpose is to increase engagement by participants in specific fields or activities (for example, training, education, marketing). ${ }^{9}$ The reasons for the extraordinary results of gamification in increasing the efficiency of social processes is still discussed: some scholars underline the role of personal motivation, others the search for fulfilment in the gaming experience or the satisfaction given by the concentration of one's resources in a personal challenge. ${ }^{10}$ Its usage has greatly spread due to the deployment of ITCs and web services, which enables to share resources, communicate worldwide and aggregate extensive virtual communities among users devoted to similar interests.

Gamification tools has been recently developed also in the public sphere for several purposes. ${ }^{11}$ Undoubtedly, a great contribution was brought by the exponential growth of ITCs and the consequent digitalization of public services. However, this does not entirely explain the reasons why gamification seems to be increasingly appealing to engage citizens, particularly to promote civic participation. ${ }^{12}$ We can offer several examples on this extent. In 2011 a speed camera lottery named Hastighets Lotteriet involved Stockholm drivers by rewarding those who respected the speed limit with the money raised from the fines of those who exceeded the limits. ${ }^{13}$ The use of lotteries and the monopoly of gambling to raise revenues by States was already known by the science of finance, but in this case the revenue is redistributed to the citizens on the basis of an evaluation of its conduct, thus fostering participation.

This year, The Republic of San Marino - located in central Italy - announced the San Marino Low Carbon Ecosystem, a platform thanks to which the government intends to encourage environmentally sustainable practices. The «green citizens» will gain a utility token to be spent on public services. ${ }^{14}$ This example is significant because gamification is combined with the use of distributed ledger technologies.

The widespread trend towards a «gamified» e-Governance and e-Democracy can be analysed from two complementary points of view. The problems due to the an/if - the first-time adoption of gamification in the public sphere - should also be seen in the light of the quomodo/how - the large amount of personal data and the relative automated decision-making processes -. This consideration leads to a sensitive issue, exemplified by the Chinese Social Credit System (SCS), which is due to be entirely enforced by next year. As many

7 DeKoven, The well-played game: a player's philosophy, Anchor Press, Garden City, N.Y., 1978.

8 «Gamification» has been defined «the use of game design elements in non-game contexts». Deterding/Dixon/KHALED/NACKE, From game design elements to gamefulness. Proc. Of The Proceedings of the 15th International Academic MindTrek Conference on Envisioning Future Media Environments - MindTrek «11, p. 9-15 (p. 10) DOI= http://dx.doi.org/10.1145/2181037.2181040 (2011). A more business-oriented definition is the following «a process to enhance a service with affordances for gameful experiences in order to support user's overall value creation» Huotari/Hamari, Defining Gamification - A Service Marketing Perspective. Proceedings of the 15th International Academic MindTrek Conference on Envisioning Future Media Environments - MindTrek «12, 2012, p. 17-22, (p. 19).

9 There are nine different fields of application: commerce, education, health, intra-organizational systems, sharing, sustainable consumption, work, innovation and data gathering, HAMARI/KoIvisTo/SARSA, Does Gamification Work? - A Literature Review of Empirical Studies on Gamification. In proceedings of the 47th Hawaii International Conference on System Sciences, Hawaii, USA, January 6-9, 2014., 2014.

10 Matallaoui/Hanner/Zarnekow, Introduction to Gamification: Foundation and Underlying Theories. In: Stieglitz, S./Lattemann, C./Robra-Bissantz, S./Zarnekow, R.d. and Brockmann, T. (Eds.), Gamification. Using Game Elements in Serious Contexts, Progress in IS Springer, Cham, 2017, p. 3-18.

11 VANOLO, Cities and the politics of gamification, Cities, volume 74, 2018, p. 320-326.

12 Coronado Escobar/Vasquez Urriago, Gamification. Proceedings of the 8th International Conference on Theory and Practice of Electronic Governance - ICEGOV «14, 2014, p. 514-515, AL-YAFI/El-MaSRI, Gamification of e-Government Services: A Discussion of Potential Transformation, Twenty-second Americas Conference on Information Systems, San Diego, 2016, 2016, HASSAN, Governments Should Play Games, Simulation \& Gaming, volume 48, issue 2, 2016, p. 249-267.

13 http://theinspirationroom.com/daily/2011/volkswagen-speed-camera-lottery/.

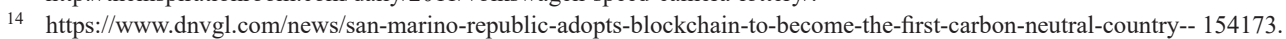


know, SCS is said to be the first ever «IT-backed authoritarianism experience» in the world..$^{15}$ Indeed, it is an IoT/IoE-based political initiative that, by collecting and processing information on people and companies, monitors and adjusts human behaviour through a reward and punishment system. ${ }^{16}$ This example is peculiar because it integrates gamification strategies with automated-decision algorithms deployed by public authorities, financial databases and several kinds of commercial services (dating and gambling websites, internet service providers).

In our contribution we intend to explore some concerns rising from the use of gamification by public institutions, by proposing a theoretical-practical-mixed approach with particular regard to legal aspects. In order to address such a topic, we will proceed as follows. First, we draw a theoretical overview of some interesting recent experiences, providing an evaluation of their outcomes. After that, we deepen the analysis of concerns for the protection of fundamental rights and privacy in the EU GDPR framework. ${ }^{17}$ Then, we describe a proposal providing the individual collection and public allocation of «civic points» as a viable solution, fostering aggregating processes of political participation while minimizing the risks of political abuse and massive surveillance. At the end, we offer a few final considerations and draw paths for future research.

\section{Theoretical background of gamification as a tool for participative governance}

In western political science, representation and participation are two conflicting concepts. On the one hand, in most cases the representative can be chosen by the represented (in the Middle Ages he was delegated on the basis of a private-law contract) but this connection is not indispensable to constitute the power to act on behalf of the political community (such prerogative could also be based on a self-investiture, as happens in authoritarian regimes). ${ }^{18}$ On the other, an extensive popular participation turns into a direct exercise of power, so becoming useless the institution of representation in itself. These two ideas are not only mutually exclusive in theory, but they both can also be biased when put into practice. Representative institutions struggle to find a balance between the opportunity to establish clear boundaries in order to avoid abuses of power and the need to guarantee freedom of action for representatives, so political immunity for representatives is a paradigmatic measure in this sense. Conversely, the lack of reliance in political institutions leads to an exodus of voters at electoral ballots, hence it can be said that social members exclude themselves from interaction with institutions. Only if harmonically combined, these two tenets can create a political community joint to the pursuit of the common good.

Recently, in order to address the lack of political involvement by citizens with an inclusive approach, gamification has been adopted to trigger social aggregation and participative decision-making ${ }^{19}$. In this sense, it is

15 In this sense, MeISSNER/WÜBBEKE, IT-backed authoritarianism: Information technology enhances central authority and control capacity under Xi Jinping. In: Heilmann, S. and Stepan, M. (Eds.), China's Core Executive. Leadership styles, structures and processe s under Xi Jinping, Mercator Institute for China Studies (MERICS) Mercator Institute for China Studies, Berlin, 2016, p. 52-57. According to some studies, a consistent part of Chinese public opinion endorses the attempt to enforce social «harmony», even though it entails video surveillance and geolocalization at national and local level, KostKA, China's social credit systems and public opinion: Explaining high levels of approval, New Media \& Society, volume 21, issue 7, 2019, p. 1565-1593.

16 See Keats Citron/Pasquale, The Scored Society - Due Process for Automated Predictions, Washington Law Review, volume 89, issue 1, 2014, p. 1-33, Liang/Das/Kostyuk/Hussain, Constructing a Data-Driven Society: China's Social Credit System as a State Surveillance Infrastructure, Policy \& Internet, volume 10, issue 4, 2018, p. 415-453, ENGELMAnN/Chen/Fischer/KAo/GrossKLAGS, Clear Sanctions, Vague Rewards. How China's Social Credit System Currently Defines «Good» and «Bad» Behavior. Proc. Of The Proceedings of the Conference on Fairness, Accountability, and Transparency - FAT* «19, p. 69-7810.1145/3287560.3287585 (2019).

17 Regulation (EU) 2016/679 of the European Parliament and of the Council of 27 April 2016 on the protection of natural persons with regard to the processing of personal data and on the free movement of such data, and repealing Directive 95/46/EC (General Data Protection Regulation, henceforth GDPR), OJ L 119, 4.5.2016, p. 1-88.

18 Dovi, Political Representation. In: Zalta, E.N.: The Stanford Encyclopaedia of Philosophy, Stanford, Stanford University (2018).

19 Shirk,, Here comes everybody: the power of organizing without organizations, Penguin Press, New York, 2008. 
noteworthy that ICTs are exploited to foster spontaneous aggregation processe ${ }^{20}$ without garbling pre-existing social relations ${ }^{21}$ and, we may argue, it is precisely the fact that such artificial processes are «gamified» that allows participants to abide them separately from ordinary social rules.

This approach is centred on a vision according to which public authorities - the State in particular - are no longer severe custodians of the status quo but driver of social innovation. ${ }^{22}$ The traditional belief that law should be certain and its application should be rigorous is overruled by the need for the law to be established through experimentation ${ }^{23}$ and for political decisions to be the result of inclusive approaches. In this perspective, each citizen should recognize herself/himself as a component of the political community participating in a social practice that favours the emergence of the awareness of common problems and their possible solutions as a form of «implicit knowledge» of the individual, embedded in her/his gaming patterns.

\section{Gamification and the control of citizens' personal data}

It may be true that «citizen participation is citizen power», as written some time ago by SHERRY R. ARNSTEIN in one of the most popular studies on the subject ${ }^{24}$ however, recently we have witnessed how, thanks to ICTs, the very concept of people's participation has evolved into a form of information sharing between institutions and citizens, states and business companies. This change of scenario suggests to consider, besides the substantial problems of legitimacy of decision-makers, and of the righteousness of their choices, how the data related to such decisions are processed. In other words, currently it can be said that «citizen participation is citizens» data control», and control is precisely the problem emerging in all participatory processes, including those involving gamification. In this section we intend to address briefly two main aspects, concerning respectively the risk to human rights in general and the issues related to privacy with special regard to the EU GDPR.

\subsection{Gamification and human rights}

In her contribution, Arnstein provides an interesting distinction among levels of participation depending on the degree of involvement: (1) «manipulation», in which the involvement has the sole purpose of persuading on decisions already made; (2) «therapy», in which public intervention is imposed on the false assumption of the existence of alleged public health needs; (3) «informing», in which communication by the power can be mixed with disinformation in order to take advantage of information asymmetry; (4) «consultation», in which citizenship is given the opportunity to express their opinion (for example, through surveys), however without any guarantee that it would be taken into consideration; (5) «placation», when it is implemented a sort of cooptation yet, due to its intrinsic limitations, it is ineffective and instead ends up justifying top-down decisions; (6) «partnership», in which an effective negotiation is carried out between those who hold the power to execute them and those who bear their consequences; (7) «delegated power», in which citizens become accountable for the actions that involve the community; (8) «citizen control», in which the ultimate respon-

20 This vision seems to be based on the underlying assumption that social order can raise spontaneously from disorder, and evolve autonomously finding its own balance, HAYEK, Law, legislation and liberty. A new statement of the liberal principles of justice and political economy, University of Chicago Press, Chicago, 1973, Luhmann, Soziale Systeme. Grundriss einer allgemeinen Theorie, Suhrkamp, Frankfurt am Main, 1984.

21 Pagallo, Good Onlife Governance: On Law, Spontaneous Orders, and Design. In: Floridi, L. (Ed.), The Onlife Manifesto Springer International Publishing, 2015, p. 161-177.

22 Floridi (Ed.), The Onlife Manifesto. Being Human in a Hyperconnected Era, Open Access Springer International Publishing, Cham, 2015.

23 In this sense, it is noteworthy that the recent phenomena of «regulatory sandboxes» enacted by policy makers in order to experiment with new rules for disruptive technologies (such as autonomous vehicles and blockchain), see ZeTZSCHE/BUCKLEY/BARBERIS/ARNER, Regulating a revolution: from regulatory sandboxes to smart regulation, Fordham Journal of Corporate \& Financial Law, volume XXIII, 2017, p. 31-103.

24 Arnstein, A Ladder of Citizen Participation, Journal of the American Planning Association, volume 35, issue 4, 1969 , p. $216-224$. 
sible for the decisions is appointed directly to the members of the community. Such a distinction, although discussed ${ }^{25}$ shows how each ladder rung raises different kinds of issues, each of whom have to be evaluated when implementing participatory processes.

Therefore, gamification strategies have to be adopted carefully since they can bring advantages as well as downsides. It may be observed that, according to the «ladder of participation» above depicted, the benefits can be limited but still significant, since they can be placed only in the middle of the scale, provided that the involvement of participants neither remains a passive partaking, nor implies an effective embodiment of responsibility. On the contrary, gamification can not only hinder real citizens' participation at every level, but also weaken their fundamental freedoms through the abuse of information gathered through it, especially if it is engineered on IT platforms. In particular, the system of awards, bonuses and penalties enacted in the platform can affect heavily everyday existence of the participants and their families. Indeed, if who owns the platform ascertains which action is required to gain or lose points, then it can easily influence not only the «ranking» position in the game, but also the set of ethical values of the community - what is qualified «good» or «bad» - and thus the social reputation of its members. Moreover, personal data collected from the game can be used against the participants themselves, for example allowing or denying access to public services (health, transport, assistance), or as a tool for predictive policing, or even just to manipulate consensus and silence dissent. Hence, gamification can be considered as a powerful tool to increase the effectiveness of more complex inclusive policies, but it cannot be expected to work alone. It could contribute to improve civic engagement, as well as to increase the sense of belonging and the perceived participative power, thus driving institutions away from lack of trust and disillusion, but such goals should actually be pursued by the political regime.

\subsection{Gamification and personal data in the GDPR framework}

In this section we focus in particular on three aspects ${ }^{26}$, respectively concerning (1) the respect of fundamental principles (Article 5) and of lawfulness for data processing (Article 6); (2) the compliance with the legal provisions which constitute the most relevant innovation in GDPR; (3) the safeguards provided for profiling and especially automated-decision making which, not surprisingly, raise many concerns.

As regards the first aspect, it is important to emphasise that gamification requires a very careful preliminary planning in the flow of information in order to observe particularly the principles of «purpose limitation» (Article $5 \S 1(\mathrm{~b})$ ) and «minimization» (Article 5§1(c)). Moreover, the intrinsic complexity of the game could make it difficult to establish if a specific data processing is based on the consent of the data subject (Article $6 \S 1(\mathrm{a}))$ or on the existence of a public interest (Article $6 \S 1$ (e)), or even on the presence of a legitimate interest of any external entity that could manage the technologies involved (Article 6\$1(f)). In this sense, the choice of the rules of the game and the design of the rewarding scheme become crucial in pursuit both of accountability (Article 5§2) and transparency (Article 12).

Concerning the second profile, various questions emerge on the qualification of the actors and on the separation of their respective limits of responsibility. Indeed, depending on how resources are shared, processes are arrayed and applications are organized, a public institution - for example, a local municipality - could be data controller (Article 4(7) and Article 24) or joint controller (Article 26), but also data processor ((Article 4(8) and Article 28)). Of course, in this regard, keystone is the adoption of security measures (Article 32) and of models of privacy by design (Article 25§1) and privacy by default (Article 25§2), yet this cannot be possible

25 Connor, A new ladder of citizen participation, National Civic Review, issue 77, 1988, p. 249-257.

26 As a matter of fact, a widespread implementation of gamification techniques is possible only with sophisticated IT infrastructures and intensive control of resources, processes and data. Consequently, privacy concerns have to be addressed to comply with legal requirements, as well as to be trusted by users. 
without a thorough Data Protection Impact Assessment (Article 35), which in these cases seems quite inevitable yet difficult to put into practice.

Referring to the third aspect, it is worth emphasizing that the GDPR imposes a general prohibition on the automated decision-making (Article 22§1) except for some specific hypotheses to be interpreted restrictively. ${ }^{27}$ It is worthwhile that «profiling» is not forbidden as such (Article 4 (4)), neither it is an automated decisionmaking process which involves a «significant human intervention». ${ }^{28}$ In fact, it may be argued that such provisions could limit indeed the adoption of gamification techniques in an EU participative decision-making process, however they could not make them inevitably illegal: the ultimate criteria, quite obviously, is the respect of the fundamental rights and freedoms of the citizens. For the sake of precision, it might be added that a gamification platform including an automated decision-making process could be legally authorized by EU when complemented «with suitable measures to safeguard the data subject's rights and freedoms and legitimate interests» (Article 22§2(b)).

\section{Towards gamification of public engagement: the perspective of «civic points»}

In this section we intend to describe a model of participative gamification that can effectively contribute to the involvement of citizens in politics, minimizing the risks of abuses by the government ${ }^{29}$. In this sense, it could be qualified as an «ethical» use of gamification. ${ }^{30}$

We assume that such model is placed within a legal system which allows the public authority - for example, a local municipality - to allocate a certain amount of finances in a participatory budget, that is, funds whose destination is left to the direct decision of the members of the community. Citizens can decide, for example, if such budget should be spent for building a new swimming pool, or creating three playgrounds, or even renovating a school. In other words, citizens do not even touch the money, they just decide how the public institution should devote it.

Through the mechanism of gamification, it is determined who can actually participate in the decision on the participative budget, assigning the right to vote and graduating its weight depending on the complexity of the activities carried out while y citizens engaged in the life of the community. For example, volunteering for a cultural foundation or a charity allows to earn «civic points» which can be converted into votes when it comes the time - for example, every year - to vote on the proposal submitted to the participatory budget.

The collection of «civic points» is made possible by a web application that allows validation mechanisms by third parties. For example, when a citizen devotes her/his time to a charitable cause, she/he receives the «civic points» from the association organizing such activity, which has been previously been authorized to do so by the administrative authority. All this happens through a web application that contains the user profiles of all participants and which allows them to express their vote on the participative budget.

This model allows citizens to increase their commitment to the community without concerns for their fundamental freedoms. Another great advantage in this system is that citizens do not act out of self-interest, because they do not receive any direct or indirect benefit from the distribution of resources. With gamification their voice is just louder.

27 Such provisions require the negotiation or the performance of a contract, a legal authorization by the EU or a Member State or the consent of the Data subject (Article 22\$2).

28 See: Guidelines on Automated individual decision-making and Profiling for the purposes of Regulation 2016/679 (WP251).

29 Coppola, Civic Points, in 5th Italian Conference on ICT for Smart Cities And Communities, 18-20 September, 2019, Pisa (IT), http://icities2019.unipi.it/program.shtml\#.

30 Marczewski, The ethics of gamification, XRDS: Crossroads, The ACM Magazine for Students, volume 24, issue 1, 2017, p. 56-59, Kim/Werbach, More than just a game: ethical issues in gamification, Ethics and Information Technology, volume 18, issue 2, 2016, p. $157-173$. 


\section{Conclusion}

Although game has always been experienced by humankind, only recently it has been proposed as a tool to encourage civic engagement. We have shown that governments are using gamification for different purposes, also thanks to the growth of ICTs, not only by collecting personal data from citizens but also by implementing automated decision processes. We argue that such initiatives entail obvious benefits but also serious threats especially concerning privacy and other fundamental rights and freedoms of individuals, as exemplified having regard to the EU GDPR. The proposal presented in this contribution, concerning the collection and distribution of «civic points» as a measure of weighting citizens' involvement in participative budget, aims at fostering participation in decision-making processes at a local level minimizing risks of abuses by political authorities.

The importance of gamification will raise in academic discussion as well as in public debates and in political arenas. Despite it is not manipulative per se or prone to abuses any more than other communication tools or social artefacts, there is still a lack of awareness on its real potentials. For the future, we intend to proceed further in the analysis of this field of research in order to evaluate its ethical legitimacy, legal framework and social implications.

\section{References}

Al-Yafi, Karim/El-MaSri, Mazen, Gamification of e-Government Services: A Discussion of Potential Transformation, Twenty-second Americas Conference on Information Systems, San Diego, 2016, 2016.

Arnstein, Sherry R., A Ladder of Citizen Participation, Journal of the American Planning Association, volume 35, issue 4, 1969, p. 216-224.

Caillois, Roger, Les Jeux et les Hommes. Le Masque et le Vertige, Gallimard, Paris, 1958.

Connor, Desmond M., A new Ladder of Citizen Participation, National Civic Review, issue 77, 1988, p. $249-257$.

Coppola, Paolo, Civic Points, in 5th Italian Conference on ICT for Smart Cities And Communities, 18-20 September, 2019, Pisa (IT), http://icities2019.unipi.it/program.shtml\#.

Coronado Escobar, Jesús Eduardo/Vasquez Urriago, Angela Rocio, Gamification, Proceedings of the 8th International Conference on Theory and Practice of Electronic Governance - ICEGOV'14, 2014, p. 514-515.

DeKoven, Bernie, The Well-played Game: a Player's Philosophy, Anchor Press, Garden City, N.Y., 1978.

Deterding, Sebastian/Dixon, Dan/Khaled, Rilla/Nacke, Lennart, From Game Design Elements to Gamefulness. Proceedings of the 15th International Academic MindTrek Conference on Envisioning Future Media Environments - MindTrek'11, p. 9-15 DOI= http://dx.doi.org/10.1145/2181037.2181040, 2011.

Dovi, SuZanne, Political Representation. In: Zalta Edward N.: The Stanford Encyclopaedia of Philosophy, Stanford, Stanford University, 2018.

Engelmann, Severin/Chen, Mo/Fischer, Felix/Kao, Ching-Yu/Grossklags, Jens, Clear Sanctions, Vague Rewards. How China's Social Credit System Currently Defines «Good» and «Bad» Behavior. Proceedings of the Conference on Fairness, Accountability, and Transparency - FAT* «19, p. 69-78 DOI= http://dx.doi.org/10.1145/3287560.3287585, 2019. FINNIS, JoHn, Natural Law and Natural Rights, Clarendon Press, Oxford, 1980.

Floridi, Luciano (Ed.), The Onlife Manifesto. Being Human in a Hyperconnected Era, Open Access Springer International Publishing, Cham 2015.

Hamari, Juho/Koivisto, Jonna/Sarsa, Harri, Does Gamification Work? - A Literature Review of Empirical Studies on Gamification, In proceedings of the 47th Hawaii International Conference on System Sciences, Hawaii, USA, January 6-9, 2014, 2014.

Hassan, Lobna, Governments Should Play Games, Simulation \& Gaming, volume 48, issue 2, 2016, p. $249-267$.

Hayek, Friedrich A. von, Law, Legislation and Liberty. A new Statement of the Liberal Principles of Justice and Political Economy, University of Chicago Press, Chicago, 1973.

Huizinga, JoHan, Homo ludens. Versuch einer Bestimmung des Spielelementes der Kultur, Pantheon, Amsterdam, 1939. 
Huotari, Kai/Hamari, Juho, Defining Gamification - A Service Marketing Perspective, Proceedings of the 15th International Academic MindTrek Conference on Envisioning Future Media Environments - MindTrek'12, 2012, p. 17-22.

Keats Citron, Danielle/Pasquale, Frank, The Scored Society - Due Process for Automated Predictions, Washington Law Review, volume 89, issue 1, 2014, p. 1-33.

Kim, Tae Wan/Werbach, Kevin, More than Just a Game: Ethical Issues in Gamification, Ethics and Information Technology, volume 18, issue 2, 2016, p. 157-173.

Kostka, Genia, China's Social Credit Systems and Public Opinion: Explaining high Levels of Approval, New Media \& Society, volume 21, issue 7, 2019, p. 1565-1593.

Liang, Fan/Das, Vishnupriya/Kostyuk, Nadiya/Hussain, Muzammil M., Constructing a Data-Driven Society: China's Social Credit System as a State Surveillance Infrastructure, Policy \& Internet, volume 10, issue 4, 2018 , p. $415-453$.

Luhmann, NikLas, Soziale Systeme. Grundriss einer allgemeinen Theorie, Suhrkamp, Frankfurt am Main, 1984.

Marczewski, Andrzej, The Ethics of Gamification, XRDS: Crossroads, The ACM Magazine for Students, volume 24, issue 1,2017 , p. 56-59.

Matallaoui, Amir/Hanner, Nicolai/Zarnekow, RüDiger, Introduction to Gamification: Foundation and Underlying Theories. In: Stieglitz Stefani, Lattemann Christoph, Robra-Bissantz Susanne, Zarnekow Rüdiger, Brockmann Tobias (Eds.), Gamification. Using Game Elements in Serious Contexts, Progress in IS Springer, Cham, 2017, p. 3-18.

MeISSNER, MirJam/WüBbeKe, Jost, IT-backed Authoritarianism: Information Technology Enhances Central Authority and Control Capacity under XI JiNPING. In: Heilmann Sebastian, Stepan Matthias (Eds.), China's Core Executive. Leadership Styles, Structures and Processes under XI JINPING, Mercator Institute for China Studies (MERICS) Mercator Institute for China Studies, Berlin, 2016, p. 52-57.

Pagallo, Ugo, Good Onlife Governance: On Law, Spontaneous Orders, and Design. In: Floridi Luciano (Ed.), The Onlife Manifesto Springer International Publishing, 2015, p. 161-177.

Shirky, Clay, Here Comes Everybody: the Power of Organizing without Organizations, Penguin Press, New York, 2008. Vanolo, Alberto, Cities and the Politics of Gamification, Cities, volume 74, 2018, p. 320-326.

Wittgenstein, Ludwig, Philosophical Investigations, Blackwell, Oxford, 1953.

Zetzsche, Dirk A./Buckley, Ross P./Barberis, Janos N./Arner, Douglas W., Regulating a Revolution: from Regulatory Sandboxes to Smart Regulation, Fordham Journal of Corporate \& Financial Law, volume XXIII, 2017, p. 31-103. 